\title{
World Radiocommunication Conference 12: Implications for the Spectrum Eco-System*
}

\author{
Mohamed El-Moghazi ${ }^{1}$, Jason Whalley ${ }^{2}$, James Irvine ${ }^{3}$ \\ Department of Management Science, \\ Strathclyde Business School \\ University of Strathclyde, Glasgow, UK \\ ${ }^{1}$ mohamed-ali-elmoghazi-ali@strath.ac.uk \\ jason.whalley@strath.ac.uk \\ Department of Electronic \& Electrical Engineering, \\ University of Strathclyde, Glasgow, UK \\ ${ }^{3} \mathrm{j} . \mathrm{m} . \mathrm{irvine@strath.ac.uk}$
}

\begin{abstract}
Spectrum allocation is once more a key issue facing the global telecommunications industry. Largely overlooked in current debates, however, is the World Radiocommunication Conference (WRC). Decisions taken by WRC shape the future roadmap of the telecommunications industry, not least because it has the ability to shape the global spectrum allocation framework. In the debates of WRC-12 it is possible to identify three main issues: enhancement of the international spectrum regulatory framework, regulatory measures required to introduce Cognitive Radio Systems (CRS) technologies; and, additional spectrum allocation to mobile service.

WRC-12 eventually decided not to change the current international radio regulations with regard to the first two issues and agreed to the third issue. The main implications of WRC-12 on the spectrum ecosystem are that most of actors are not in support of the concept of spectrum flexibility associated with trading and that the concept of spectrum open access is not under consideration. This is explained by the observation that spectrum trading and spectrum commons weaken state control over spectrum and challenge the main principles and norms of the international spectrum management regime. In addition, the mobile allocation issue has shown the lack of conformity with the main rules of the regime: regional spectrum allocation in the International Telecommunication Union (ITU) three regions, and the resistance to the slow decision making procedures. In conclusion, while the rules and decision-making procedures of the international spectrum management regime were challenged in the WRC-12, the main principles and norms are still accepted by the majority of countries.
\end{abstract}

Keywords: WRC-12, cognitive radio, trading, spectrum policy, ITU.

\footnotetext{
${ }^{*}$ The authors are solely responsible for the opinions expressed in this paper.
} 


\section{Introduction}

A spectrum divide has emerged in which there is shortage in radio spectrum, a critical component in the delivery of wireless services. The spectrum divide is a direct consequence of the inefficient 'command and control' spectrum management regime that focuses mainly on technical aspects such as avoiding interference while creating an artificial scarcity of spectrum due to inefficient utilisation (Wellenius and Neto, 2005).

The literature suggests two alternatives regimes to overcome such deficiencies. The first one, 'spectrum trading' calls for treating spectrum assignments in a similar way to other property rights and allowing spectrum usage flexibility so that service and technology neutrality occur (Coase, 1959; Hazlett, 1998). Once spectrum property rights are defined, trading is then applied to capture the inherent economic efficiency of the market (Cave and Webb, 2003). The second regime, 'spectrum commons' is based on technologies such as cognitive radio systems (CRS) that enable spectrum open access to all users and as a result render license exclusivity and spectrum scarcity obsolete (Baran, 1995; Benkler, 1998; Gilder, 1994; Noam, 1995; Noam, 1998). Commons advocates argue that spectrum should be managed in a decentralized way, with the regulator focusing on regulating equipment use and controlling traffic rather than spectrum.

With this in mind, this paper focuses on the ITU WRC-12 meeting that was held in Switzerland at the start of 2012. This meeting was convened to discuss how the spectrum management framework could be enhanced as well as measures to introduce CRS and additional spectrum allocation to the mobile service. The remainder of this paper is divided into six main sections. In the following main sections, the international spectrum management regime is analysed (Section 2) and the spectrum ecosystem is outlined in terms of key actors, relations and changes in Section 3. This is then followed in Section 4 by a brief description of three key areas 
debated at WRC-12, before Section 5 explores the implications of these debates for the spectrum ecosystem. A discussion is being drawn in Section 6 while concluding remarks are provided in Section 7.

\section{International Spectrum Management Regime}

Radio spectrum was perceived in the early days of wireless communications as a new inexhaustible natural resource commonly and freely used by the public (Struzak, 2003). However, two issues necessitated managing the spectrum at the national and international levels. The first of these is the phenomena of interference, which became a major problem as radios transmitted over a wide band of frequencies and radio emissions crossed frontiers. This caused interference in neighbouring countries. The second issue was the refusal of the Marconi company to relay messages received from competing operators (Anker and Lemstra, 2011). These two issues encouraged a shift in how spectrum was perceived, from a commodity to a natural resource whose usage needed to be managed (Kruse, 2002). Accordingly, an international conference was held in Berlin in 1903 to address the Marconi company monopoly over radio telegraphy and to enable international interconnection (Codding, 1991). The final protocol of the conference established that wireless stations should operate in a way as not to interfere with other stations (Codding and Rutkowski, 1982). Following that, the interest of many entities, such as military and broadcasters, in spectrum started to grow, which, in turn, motivated governments to heavily regulate spectrum usage (Ryan, 2012). This was in line with the national policies at the turn of the twentieth century which sought to enforce government control over radio spectrum for political purposes such as national security and for economic benefits derived from controlling the industry (Cowhey, 1990). 
By the mid-1920s, the issue of harmful interference became more serious as Europe and North America were full of broadcasting stations using unregulated frequencies (Savage, 1989). Accordingly, the 1927 International Radiotelegraph Conference witnessed shift from focusing on the regulation of the radio traffic towards allocating the spectrum to separate services (Woolley, 1995), and the concept of "common use of common frequencies" was gathering more momentum (Levin, 1971). The main principles of the international spectrum management regime $^{1}$ are the sovereign right of each state to assign its frequencies to any service or station (Lyall, 2011), and that all radio stations must not cause harmful interference to other stations which operate in accordance with the provisions of the ITU radio regulations (ITU-R, 2008e). The main norm of the regime is global harmonization of spectrum allocation. The radio sector of the ITU (ITU-R) is the administrative cooperation body responsible for setting the regime's rules through the radio regulations and the ITU-R resolutions, recommendations and reports. The radio regulations have international treaty status and they are binding for all the ITU-R countries (Maitra, 2004).

The regime's rules include registering national frequencies in the ITU-R Master International Frequency Register (MIFR) in order to acquire international recognition and protection against harmful interference. Such registration requires conformity with the ITU-R service allocation table and not causing harmful interference to existing assignments in other countries (Lyall, 2011). A second rule is that allocating each spectrum band to one or more radio services with equal or different rights (primary and secondary). This is based on the results of compatibility and sharing studies that are usually technology dependent (Louis, 2011). Stations

\footnotetext{
${ }^{1}$ Regimes can be defined as sets of implicit or explicit principles (beliefs of facts, causation, and rectitude), norms (standards of behaviour defined as rights and obligations), rules (specific prescriptions and proscriptions for action), and decision-making procedures (prevailing practices for making / implementing collective choices) around which actors' expectations converge in a given area of international relations (Krasner, 1982).
} 
of a secondary service cannot cause harmful interference to stations of primary services and cannot claim protection from harmful interference caused by stations of a primary service (ITU$\mathrm{R}, 2008 \mathrm{c})$. A third rule is that of regional allocation, where the ITU divides the world into three regions in terms of spectrum allocation ${ }^{2}$.

\section{Spectrum Ecosystem}

By outlining the 'spectrum ecosystem' we aim to understand the complex set of relationships and interactions between actors and perspectives within the international spectrum policy domain. Adopting such an approach enables us to examine the factors that formulise the decision making process. As noted by Fransman (2010), the ecosystem metaphor is useful in understanding dynamic processes that accommodate different interacting forces.

An ecosystem refers to an environment where the interacting actors benefit from each other's participation via symbiotic ${ }^{3}$ relationships (Sardenberg, 2010). The elements of an ecosystem are divided into biotic components, which include operators, manufacturers and end users, and abiotic components which refer to the environment including economic factors and political situation (Yuncuia and Gangb, 2011). Actors within the ecosystem conduct maintenance to their living environment while the environment promote their survival and development (Dong et al., 2007).

The rules of actor interactions in the ecosystem are determined by institutions, which include financial institutions, regulators, competition authorities and standardization bodies (Fransman, 2010). The interaction between the different actors is influenced by the platform at

\footnotetext{
${ }^{2}$ Region 1 comprises Europe, Africa, the Middle East west of the Persian Gulf including Iraq, the former Soviet Union and Mongolia. Region 2 covers the Americas, Greenland and some of the eastern Pacific Islands. Region 3 contains most of non-former-Soviet-Union Asia, east of and including Iran, and most of Oceania.

${ }^{3}$ The word 'symbiosis' comes from the Greek meaning living together.
} 
the heart of the ecosystem. Industry platforms are defined as the building blocks that act as a foundation upon which an array of firms can develop complementary products, technologies or services (Gawer, 2010). In our case, the main platform on which the ecosystem is based is radio spectrum.

The spectrum ecosystem could be mapped onto four main layers: applications, technologies, frequency assignments and service allocations. These layers accommodate four main actors respectively: end users, the wireless telecommunication industry (e.g., manufactures and operators), national regulators, and the ITU-R. The main trigger for changes within the ecosystem is users' demand to a particular wireless application (e.g., mobile voice calling). This initiates three types of interaction in the technology layer to meet such demand and provide suitable technologies, namely, competition, cooperative symbiotic and learning (Fransman, 2010).

Within the frequency assignments layer, the national regulator authorises users the access to particular part of the spectrum under specified conditions according to the type of application (Cave et al., 2006). However, certainty over international spectrum allocation enable economies of scale in production (Cave, 2002). Therefore, the industry seeks through their national regulators, mostly from the developed countries, to secure their interest in the service allocation layer upon the results of discussion in WRCs.

Within WRCs, four main aspects of the spectrum are discussed: type of service (e.g., fixed, mobile), type of access (primary and secondary), allocation geographical areas (globally or regionally), and technology characteristics (e.g., maximum transmitted power). The WRC decision-making process creates technical and operational certainty for new and existing users and maximizes the global harmonization of the spectrum resource (Abernathy, 2004). Developed 
countries lead the discussion in the ITU-R and tend to influence the developing countries' position to achieve global or regional spectrum allocation. Most of the developing countries lack sufficiently knowledgeable and experienced staff to participate effectively in the discussions (McCormick, 2007).

It should be noted that vertical integration has traditionally existed between the four layers, where users' applications are provided by one technology that operates in a particular frequency band assigned by national regulator. This band is allocated to a specific service by the ITU-R. Figure 1 maps the main layers and actors within the spectrum ecosystem.

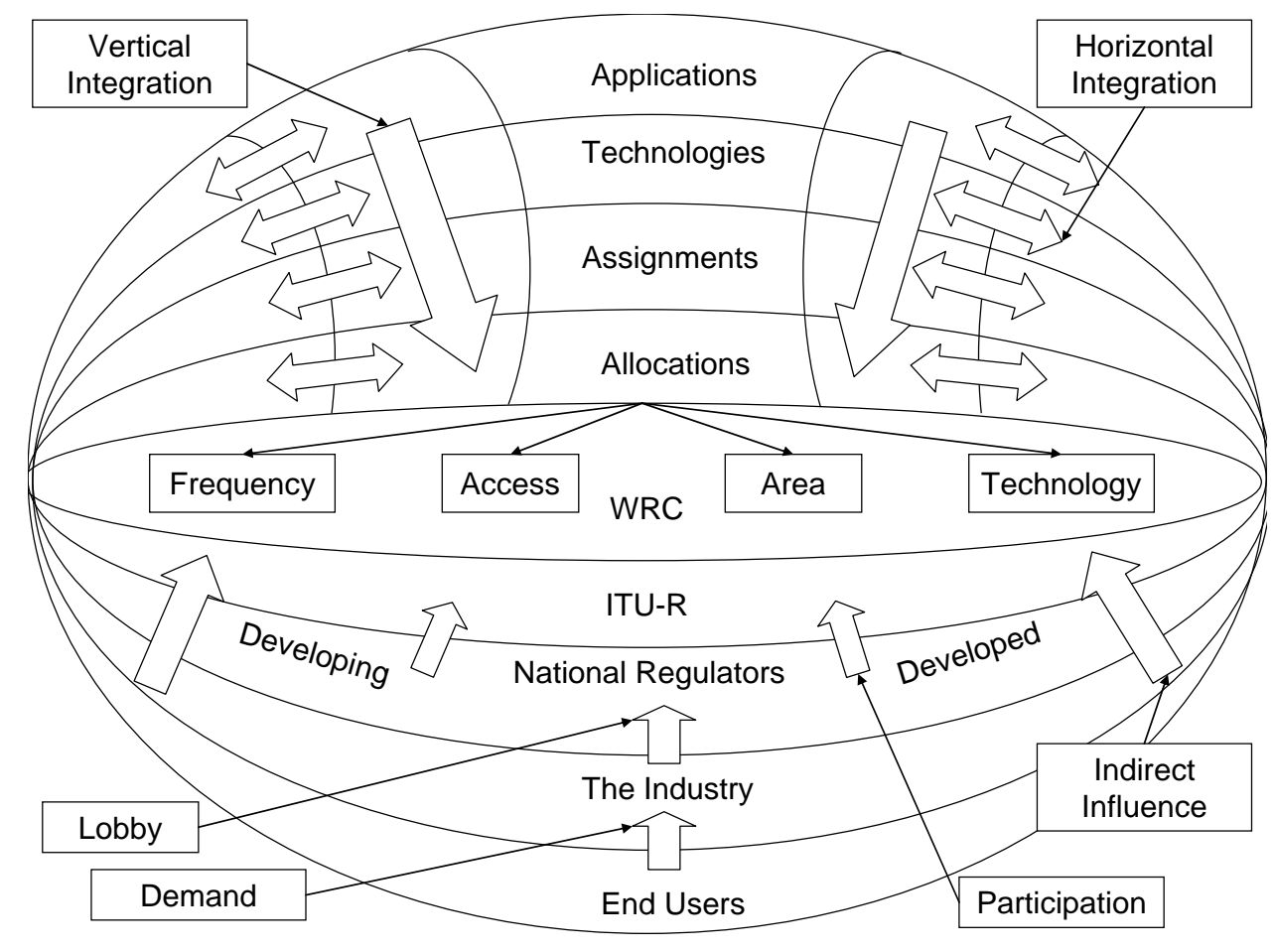

Figure 1: The Spectrum Ecosystem.

Several factors have recently influenced the spectrum ecosystem and as a result altered its structure and dynamics. Firstly, there have been changes in the traditional vertical integration that existed between the four layers of the spectrum ecosystem. With regard to the applications 
layer, the Internet's IP platform has enabled the delivery of different types of applications on the same device (Melody et al., 2005). Moreover, it has led to the involvement of a new actor in the spectrum ecosystem, namely, over the top service provider. The technology layer has also witnessed convergence between the different technologies, where the same device could be used for applications categorised across different services (e.g., providing broadcasting and mobile services via UMTS technology) (Louis and Mallalieu, 2007). Measures such as spectrum refarming have enabled spectrum licensees to modify their frequency assignments in terms of changing the used technologies and end user's applications (e.g., re-farming $2 \mathrm{G}$ spectrum to provide 3G applications) (El-Moghazi et al., 2008). Convergence in the service allocation layer occurs when the differences between hitherto standalone services become increasingly blurred (Louis and Mallalieu, 2007). All of those factors facilitate horizontal integration within each of the four layers and disassemble the vertical integration between them.

The second change in the ecosystem is the increasingly prominent role of industry in the international spectrum management regime, especially since the ITU Plenipotentiary Conference of 1995 formally recognised the rights of the private sector (MacLean, 1995). While the private sector has equal rights with national regulators in ITU-T and ITU-D, national regulators are the ultimate decision makers in the ITU-R (McCormick, 2007). However, the private sector participates and lobbies in the ITU-R to obtain support for their interests (Irion, 2009). For instance, the WIMAX forum lobbied many countries to include the WIMAX standard IEEE 802.16-2009 to the ITU IMT-2000 radio interface (ITU, 2007). Furthermore, although national regulators are the decision makers for the treaty instruments in the WRCs, their decisions are developed based on the studies of the ITU-R study groups where the private sector conducts much of the technical work (McCormick, 2007). This indirect influence of the industry in the 
ITU-R has resulted in multi-stakeholders spectrum governance based on reaching a consensus in which a large majority of those who participated agreed with one another (Waz and Weiser, 2011).

\section{World Radiocommunication Conference 2012}

The WRC is one of the ITU conferences that consider specific radiocommunication matters. The WRC resolutions and recommendations are part of the RR and have international treaty status. Significantly, the agenda of the current conference is determined by the previous one. Items that could be included in the agenda include revisions to the RR and any other question of a worldwide character that falls within the remit of the conference (ITU, 2011b). During the WRC, negotiations are conducted between member states of the ITU, which effectively involving them trading support on different issues between one another (Manner, 2003). Observers that are sector members of the ITU-R, that is, from the private sector, can attend WRCs in a non-voting capacity, while each member state is entitled to one vote (ITU, 2011b). Regional organizations usually present common proposal to the WRC on behalf on their member states. In general, those countries that do not share the view of the others regarding a WRC decision are expected to agree to the opinion of the majority. Otherwise, they can record their reservations (Jakhu, 2000).

With an attendance of approximately 3000 delegates from 153 national delegations and several companies and organizations with interest in global spectrum issues, WRC-12 discussed several issues critical for the telecommunications industry, namely: public protection and disaster relief, amateur radio and the usage of spectrum above $275 \mathrm{GHz}$ (Clegg, 2012). More specifically, three main issues were discussed at the WRC-12:

- Enhancement of the international spectrum regulatory framework; 
- Regulatory measures required to introduce CRS technologies; and,

- Additional spectrum allocation to mobile services.

The following three sub-sections will elaborate on these issues in turn.

\subsection{International Spectrum Regulatory Framework}

WRC-12 discussed under agenda item 1.2 how to enhance the international spectrum regulatory framework (ITU-R, 2007a). The issue was first raised in 1989 as part of the move towards ITU restructuring in order to adapt to the changing telecommunications environment (Woolley, 1995). It was noted that radio regulations were complex, unwieldy and difficult to apply. Accordingly, WRC-95 recommended in recommendation 34 that future WRCs should, wherever possible, allocate frequency bands to the most broadly defined services with a view to providing the maximum flexibility to ITU countries in spectrum use. In addition, it was recommended that WRCs should, wherever possible, allocate frequency bands on a worldwide basis (ITU-R, 1995).

The issue was also raised at WRC-03, motivated this time by the convergence of radiocommunications services as exemplified by services such as mobile-TV. More specifically, radio systems were perceived to have downstream and upstream channels that could operate within the same or different radio services (ITU-R, 2003a). During WRC-03, the European countries called for measures to be developed to facilitate the use of common, worldwide, frequency bands for implementing terrestrial wireless interactive multimedia applications to meet the convergence in radiocommunications services (CEPT, 2003). In contrast, however, several countries and regional organisations explained that no regulatory impediments to terrestrial wireless interactive multimedia applications have been identified and, therefore, there is no need to study the issue in future WRCs (USA, 2003; ASMG, 2003). 
Eventually WRC-03 decided that the existing regulatory framework contained sufficient flexibility to minimise any regulatory constrains resulting from the existing definitions of services (Gavrilov, 2003). However, WRC-03 also decided in resolution 951 to continue studying the effectiveness, appropriateness and impact of the radio regulations with regard to the advances in radio technologies and to identify options for improvements in radio regulations until WRC-07. The resolution considers that segregating bands for different radiocommunication services may not achieve the best possible result in terms of spectrum efficiency, and that the use of packet radio systems enables the provision of different applications within the same spectrum band. The resolution also considers that the same technology could be used in different radiocommunication services and the same applications could combine different elements of radiocommunication services (ITU-R, 2003b).

The issue was not resolved at WRC-07, which decided to continue to study the issue until WRC-12 under agenda item 1.2 (ITU-R, 2007f). Following WRC-07, the ITU-R studies approached the issue from two perspectives. The first focused only on convergence between fixed and mobile services, while the second addressed spectrum allocation issues more generally (ITU-R, 2011b). Studies prior to WRC-12 show that, in most cases, there is joint allocation of spectrum across fixed and mobile services (ITU-R, 2011b) and that while the principle of frequency band allocation for broadly defined services is applied to 41.73 per cent of allocations, it is not always applicable (ITU-R, 2011a).

During WRC-12 several regional organisations called for retaining the current practice with regard to spectrum allocation principles as there is sufficient flexibility within the existing regulatory framework and the WRC process does not impede the introduction of new technologies (APT, 2011a; ASMG, 2011a; RCC, 2011a; CITEL, 2012a). In contrast, European 
countries proposed to upgrade recommendation 34 with regard to spectrum allocation principles so that it would become a resolution (CEPT, 2011a). WRC resolutions have a higher degree of obligation and are more binding on ITU countries than WRC recommendations. With regard to convergence between fixed and mobile services, only the Americans and European countries proposed to change some of the definitions within the radio regulations with regard to these services (CITEL, 2012a; CEPT, 2011a).

Eventually WRC-12 decided not to change current spectrum allocation practices with regard to the two issues (ITU-R, 2012j), and to end the general studies of enhancing the international spectrum regulatory framework under resolution 951 as it has been considered by two successive conferences without being resolved (ITU-R, 2012f). Furthermore, WRC-12 decided to continue the studies on revising the definitions of fixed service, fixed station and mobile station till WRC-15 (ITU-R, 2012g).

In addition, the WRC-12 considered that that the issues raised by the convergence of services may not always be addressed through the redefinition of radiocommunication services and recommended that the ITU-R study all aspects of interference management for stations that may operate under more than one terrestrial radiocommunication service particularly crossborder interference cases without being one of the agenda items for the WRC-15 (ITU-R, 2012c).

\section{$\underline{4.2 \text { Cognitive Radio Systems }}$}

The second key issue that was discussed at WRC-12 under agenda item 1.19 were those regulatory measures that could enable deployment of CRS (ITU-R, 2007a). The issue was raised during WRC-07, which in resolution 956 invited the ITU-R to study measures such as the need for a worldwide harmonized cognitive supporting pilot channel (CPC) or a database that can 
assist in the determination of local spectrum usage (ITU-R, 2007b). However, the interest in CPC had reduced following the WRC-07 (Ofcom, 2012b).

During WRC-12 some concerns were expressed regarding interference between CRS and space, passive and safety services (RCC, 2011b). Countering this, however, others argued that national regulators can set operating parameters for CRS devices through equipment authorization requirements to ensure they will not cause interference (CITEL, 2012b; CEPT, 2011b). Furthermore, several regional organizations called for the development of a WRC-12 resolution to provide a framework for guidance on the study of CRS as well as guidance regarding how the use of CRS should be administered (ASMG, 2011b; ATU, 2011a; APT, 2011b).

In the end, WRC-12 did not decide on any particular measure with regard to CRS. No spectrum was allocated to CPC as it was recognised that CRS are technologies and not radiocommunication services. It was also agreed that the examination of the implementation and use of CRS in radiocommunication services should continue without the need for consideration in next WRC (ITU-R, 2012b). In addition, WRC-12 recommended that any radio system implementing CRS technology should operate in accordance with the provisions of the radio regulations and that the use of CRS does not exempt administrators from their obligations with regard to the protection others operating in accordance with the RR (ITU-R, 2012d).

\subsection{Mobile Allocation}

While the previous two issues were agenda items of WRC-12, allocating additional spectrum in the $694-790 \mathrm{MHz}$ band for mobile service in ITU Region 1 countries was not. Nor, for that matter, had the issue been studied by ITU-R. This issue was discussed primarily due to the 
pressure that arose from Arab and African countries calling for the global harmonization of the band. In other words, Arab and African countries were calling for the band to be allocated for mobile services in Region 1 as it was in ITU Regions 2 and 3 (Standeford, 2012b; Standeford, 2012d). They called for an immediate allocation of spectrum in the 694-790 MHz band, which is already allocated to broadcasting service, to meet growing broadband demand. The issue was also discussed due to pressure from the mobile industry that lobbied regional organizations prior to WRC-12 (Billquist, 2010b; Billquist, 2010a). The origin of the issue is related to the ITU Regional Radio Conference in 2006 (RRC-06) which planned the band 470-862 for digital broadcasting, and to the WRC-07 which allocated the band 790-862 MHz for mobile service on a primary basis (Beutler, 2012).

The argument presented by Arab and African countries was based on a number of points (ITU-R, 2012j). Firstly, the spectrum available in the 790-862 MHz band for mobile broadband is only the band $790-816 \mathrm{MHz}$ as the rest of the band is already used by other services. Therefore, the 694-790 MHz band is, for Arab and African countries, arguably the first digital dividend rather than the second. Secondly, the $694-790 \mathrm{MHz}$ band is already allocated in ITU regions 2 and 3 for mobile and using this band will decrease the cost of deploying such systems. Thirdly, government income arising from allocating this band to broadband mobiles service will be used to facilitate the digital switchover; thereby enabling developing countries to meet the deadline date of 2015. Fourthly, the allocation would not affect broadcasting services as sharing between mobile and broadcasting services is possible. Finally, the propagation characteristics of the 694$790 \mathrm{MHz}$ band will contribute to reducing the digital divide between developing and developed countries. 
The European countries opposed such proposals because the 694-790 MHz band is mainly allocated for broadcasting service in their territories and a large investment has already been made to fund the transition to digital television (Sims, 2012). In addition, it was argued that the issue is not a WRC-12 agenda item and had not been studied by ITU-R, and that some countries largely depend on terrestrial TV broadcasting due to the relatively low prevalence of cable broadcasting networks (RCC, 2012).

WRC-12 decided eventually to allocate the 694-790 MHz frequency band in Region 1 to mobile service on a co-primary basis with broadcasting service. The allocation is effective immediately after WRC-15 upon refinement of the lower edge of the allocation (ITU-R, 2012h). In addition, the global growth in demand for mobile broadband applications has led to the inclusion of a new agenda item at the next WRC-15 that will consider additional spectrum allocations to the mobile service on a primary basis (ITU-R, 2012i). This new agenda item was supported by all of the six regional organizations (CEPT, 2011c; APT, 2011c; ATU, 2011b; ASMG, 2011c; CITEL, 2012c; RCC, 2011c).

It is worth mentioning that several European countries recorded their reservations and stated that they agreed to reach a compromise with great reluctance, on an exceptional basis in the spirit of international cooperation and to satisfy the urgent demands of the African and Arab countries. They also stated that WRC-12 neither discussed nor clarified whether the proposals belonged to one of the agenda items of WRC-12 (Oberst, 2012).

\section{Implications for the Spectrum Ecosystem}

This section discusses the implications of decisions taken at WRC-12 for the spectrum ecosystem. The first sub-section discusses spectrum trading, while the second focuses on the notion of a spectrum commons. The third sub-section addresses mobile services. 


\subsection{Spectrum Trading}

In general, the principles underpinning the current international spectrum management regime have not been changed since the first Radio Telegraph Conference in Berlin in 1906 (ITU-R, 2012c). WRC-12 witnessed the fourth attempt after WRC-95, WRC-03 and WRC-07 to amend the current international spectrum management regime and introduce more flexibility without any success.

One possible explanation is that according to the ITU-R rules, countries applying service allocation flexibility cannot claim protection for their radio stations from harmful cross-border interference or cause harmful interference to stations operated in compliance with ITU radio regulations in other countries (ITU-R, 2008b). Meanwhile, according to article 42 of the ITU constitution member states have the right to make special arrangements on telecommunications matters as long as they do not cause harmful interference to the radio operations of other countries (ITU, 2011a).

Therefore, although ITU radio regulations do not prevent national regulators from introducing flexibility, they do not encourage such approach. Moreover, unless there is significant benefit for the national regulators to introduce flexibility and adopt spectrum trading, they will not be willing to take the risk and lose international recognition to their spectrum assignments. The concept of spectrum full flexibility is quite difficult to be applied from the technical viewpoint as it implies defining generic technology and service models (Louis, 2011). This is against the traditional service allocation undertaken in the ITU that is made based on sharing or compatibility studies assuming some form of operational environment. Furthermore, the harmonization of spectrum allocation is important to minimize possible cross-border interference between neighbouring countries when they operate different services in the same 
spectrum band. Coordination is less complicated when neighbouring countries operate the same service in the same spectrum band (Anker and Lemstra, 2011)

In addition, the practice of trading in the countries that encourage market determination of service has not proven to be widely successful (Akalu and Arias, 2012; Benkler, 2011; Cave et al., 2007). For instance, the percentage of professional mobile radio (PMR) trading transactions in the UK, the country pioneering spectrum trading, compared to the total number of licenses is just 4.3 per cent, while in France, where there are 30,000 fixed link licenses and trading is allowed, no transaction has ever happened (Electronic Communications Committee (ECC), 2011).

This is due to the nature of wireless services that limits the effectiveness of flexible spectrum rights concept. More specifically, in services such as PMR there are a large number of licensees, each with a small band of spectrum. In such cases, the trading is part of merging or change of ownership. Secondly, in services such as point-to-point fixed link (microwave link), the spectrum license is customised to the licensee's business. Therefore, it is critical to the licensee and of no importance to others. Thirdly, in the case of mobile operators, there are a small number of licensees with a large bandwidth of spectrum. Hence, the market is relatively stable and spectrum is a precious asset so that the number of trading transactions is almost zero.

No new business opportunities are presented by flexibility. The IP platform of the Internet has enabled delivering different applications including data, video and voice. This renders the need for spectrum flexibility. The cellular mobile service becomes the main service for the end users and the last years has noticed a major trend in the ITU-R towards extending the spectrum available to mobile service by hundreds of megahertz (Chaduc and Pogorel, 2008). 
It is argued that the main implication of the WRC-12 with regard to spectrum trading and flexibility is that it has affirmed that most of actors in the spectrum ecosystem are not in support of the concept as it does not provide them with any significant benefits that exceed the potential risks.

\section{$\underline{5.2 \text { Spectrum Commons }}$}

The WRC-12 decision on CRS can be explained by the fact that if the conference decided to introduce specific regulatory measures with regard to CRS, this may engender calls for a similar approach for other emerging technologies. Therefore, it is argued that there was support not to change the radio regulations rather than to promote CRS. Accordingly, CRS were recognized as a collection of technologies that could enhance spectrum utilisation efficiency and provide additional flexibility within the current international spectrum management framework.

It is also argued that the main reason for the WRC-12 decision was the recognition that deploying CRS in a country would not cause harmful interference in neighbouring countries as CRS are essentially used for short range applications (Sims, 2012). Moreover, while the decision of WRC-12 did not forbid CRS operations, it placed indirect restrictions on them by deciding that CRS must operate according to radio regulation provisions that are based on technologies that have static rather than dynamic operation parameters. More specifically, countries usually register those frequency assignments that may have international implications in the ITU-R database, MIFR, to obtain then appropriate international recognition (ITU-R, 2012a). However, such registration is required to include specific data such as frequency, location, service and transmitted power (ITU-R, 2008a). This data may not be predetermined in the case of CRS, with the result that CRS frequency assignments cannot be registered in the MIFR. 
Interestingly, while most CRS advocates previously advocated spectrum commons, during the CRS study period there was no support for CRS from either industry or academia. Among the 700 members in the ITU from the private sector, only a few are from academia ${ }^{4}$ (ITU, 2012). Furthermore, the participation of IEEE, the leading standardization organization with regard to CRS, in the discussions within the ITU-R was quite limited5 (ITU-R, 2011c; ITU-R, 2010b; ITU-R, 2010a; ITU-R, 2009a; ITU-R, 2009b; ITU-R, 2008d).

The absence of direct support from telecom operators or national regulators is due to the fact that CRS challenge the existing wireless services market as they could alter the distribution of benefits from the spectrum resource between governments and service operators. On the one hand governments will not be able to capture the huge rents that have occurred in some countries from auctioning spectrum on an exclusive basis. On the other hand, CRS would enable private businesses to deploy their internal telecommunications network independently from the main operators' network. Furthermore, vendors would be presented with the opportunity to gain a larger share of the profit to be found in the end user equipment market.

Therefore, although WRC-12 recognised CRS as technologies that do not need any particular resolution in the radio regulations, previous WRCs have issued several resolutions and recommendations to support other technologies, such as IMT, under pressure from countries with a large manufacturing sector and the industry (ITU-R, 2007d, ITU-R, 2007e, ITU-R, 2007c).

The WRC-12 decision could be considered as indirect support for the implementation of CRS because the alternative decision, to conduct band-by-band studies before using CRS, may

\footnotetext{
${ }^{4}$ For instance, no university from the UK and only three universities from the USA are members in the ITU and thus can participate in its meetings.

${ }^{5}$ Among six meetings prior to the WRC-12, the IEEE participated only once in the 5th meeting.
} 
require a future WRC agenda item for every band (Billquist, 2010c). This would delay the adoption of CRS technologies. In addition, it has been argued that the WRC-12 decision has given the go ahead for further consideration of industry proposal such as 'Authorised Shared Access' and regulatory approaches like 'Licensed Shared Access' that allow the dynamic overlay usage of the spectrum owned by mobile operators (Standeford, 2011; RSPG, 2011). It is worth noting that some regulators, such as the one in Ireland, plan to issue licences on a non-exclusive basis (Viola, 2012), and that the FCC plans to allow dynamic access not only in the TV bands but also in other licensed or unlicensed spectrum (Standeford, 2012c).

Therefore, it is argued that the main implication of the WRC-12 with regard to spectrum commons is that it has given a clear signal that the concept of spectrum open access is not under consideration. However, the WRC-12 decision could promote the development and deployment of CRS technologies within the current international spectrum management regime.

\section{$\underline{5.3 \text { Mobile Service }}$}

WRC-12 has clearly shown the dynamic interactions that occur between the various actors in the spectrum ecosystem. More specifically, although the European countries were against the Arab and African position at WRC-12, they are currently reconsidering their $700 \mathrm{MHz}$ spectrum plans (Womersley, 2012b). The UK, for instance, planned to use the $700 \mathrm{MHz}$ spectrum band for digital terrestrial TV (DTT) while allowing the use of white spaces technologies (Ofcom, 2012a). However, following the WRC-12 decision, the UK is currently considering utilizing the 600 $\mathrm{MHz}$ as part of a frequency re-plan of the DTT platform after $700 \mathrm{MHz}$ spectrum is released for mobile broadband (Ofcom, 2012a). Similar to the UK, the European countries have discussed several options for releasing $700 \mathrm{MHz}$ for mobile broadband (Standeford, 2012a). 
It is also expected that due WRC-12 African and Arab countries will re-plan their digital broadcasting spectrum so that they can use the upper part of the band currently allocated to broadcasting service for mobile services instead (Sims, 2012). Subsequent to WRC-12, calls have also been made to align mobile bands across all three ITU regions and to harmonise UHF frequencies internationally from 450 to $960 \mathrm{MHz}$ (Womersley, 2012a). Other solutions include having a single platform of converged terrestrial operators that carry both wireless broadband traffic and broadcast media content (RSPG, 2012).

However, while the WRC-12 decision has paved the way to a global harmonised spectrum in the $700 \mathrm{MHz}$ band, it has raised challenges with regard to harmonization of frequency arrangements between Asia (FDD in $700 \mathrm{MHz}$ ), Europe (FDD in $800 \mathrm{MHz}$ ), USA (FDD and TDD in $700 \mathrm{MHz}$ ), and Africa (Rancy, 2012). The WRC-12 decision has decreased the spectrum available for broadcasters by nearly $30 \%$ and will enforce them to utilize more spectrum-efficient technologies in the remaining UHF spectrum below $700 \mathrm{MHz}$ (RSPG, 2012).

WRC-12 has highlighted the increasing role of the developing countries in the ITU. For instance, Tariq Al Awadhi from the national regulator of the UAE was elected as the chairman of the conference (ITU-R, 2012k). The WRC-12 has also shown that the European countries are in a weak position in Region 1 as they do not have anymore a majority of the votes (Beutler, 2012). Furthermore, organisations like the GSMA has become increasingly influential in the spectrum ecosystem due to their greater number of offices and more frequent meetings.

It is, therefore, argued that the main implication of the WRC-12 with regard to mobile service is that it has shown how the behaviour of some actors in the spectrum ecosystem has an impact on the other actors. It has also shown the increasing direct and indirect influence of the 
developing countries and the industry in the service allocation layer. WRC-12 has proved that the main driver for change in the spectrum ecosystem are business opportunities for the industry and the presence of clear benefits for national regulators.

\section{Discussion}

It can be argued that spectrum trading and spectrum commons advocates have not succeeded in creating a new paradigm that could reshape and influence the alternatives considered by the other actors in the spectrum ecosystem (Zarkin, 2006). More specifically, the benefits from adopting both regimes are not enough to change the traditional view of spectrum management for most of the world. The tipping point at which the regime could change will arguably be reached when entrepreneurs supporting appropriate behaviour in their community have persuaded a critical mass of states to change their views (Finnemore and Sikkink, 1998). The move towards spectrum trading is encouraged mainly by national regulators in Europe as part of the telecommunications policy reform rather than by the industry (European Union, 2007). On the other hand, the notion of a 'spectrum commons' is mainly supported by academia and is largely unconsidered by national regulators.

Furthermore, from the regulatory viewpoint, trading and commons weaken state control over a valuable asset that has become a source of revenue in many countries. Both regimes threaten the main principles of the international spectrum management regime, namely, state control over spectrum and interference management. While trading transfers control over spectrum to the private sector via exclusive and flexible access, spectrum commons transfers control to end users via spectrum access etiquettes. Moreover, both regimes challenge the main norm of the regime which is global harmonization of spectrum allocation as trading enables full 
flexibility and commons provides spectrum access on demand rather than through a fixed spectrum allocation (Marshall, 2010). The main rationale behind spectrum allocation is the management of interference between radio stations (Louis and Mallalieu, 2007).

In general, WRC-12 has shown that there is great resistance from most of the ITU countries to any change in the international spectrum management regime's principles or norms. However, WRC-12 has highlighted the lack of conformity with the main rule of the regime - the regional spectrum allocation within the ITU three regions. More specifically, while Arab and African countries are located in ITU region 1 along with European countries, the WRC-12 has witnessed the tendency of them to align themselves with Asian and American countries when it comes to the issue of allocating additional spectrum for mobile services in region 1. It is worth noting that the ITU division of the world into three regions was due to a historical disagreement between the United States and Europe regarding spectrum allocation (Mazar, 2009) and because the ITU was dominated by the votes of the European countries and their colonies (Ryan, 2012).

In addition to the decline of the ITU three regions, several countries criticised the slow decision making process of WRC which can take at least eight years when it comes to allocating new spectrum or adding new service to existing allocations. The pace of change in wireless telecommunication is accelerating and the growth of mobile data demand increasing. WRC-12 recognised that there is a fairly long lead time between the identification of frequency bands by the WRCs and the deployment of systems in those bands (ITU-R, 2012e). The decision allocating spectrum to mobile services in the $694-790 \mathrm{MHz}$ band during WRC-12 without being one of the agenda items or studied beforehand was, to say the least, a significant challenge to the decision making procedures at play within the spectrum ecosystem. 
Arab and African countries were motivated to challenge the normal decision making procedures by the frequently stated observation that mobile broadband has a positive impact on the economy (Rausas et al., 2011; LECG, 2009; The World Bank, 2009). Africa is also the fastest growing mobile market in the world (GSMA, 2012). Studies have shown that among the different policies that regulators can adopt, providing spectrum in the $700 \mathrm{MHz}$ band can reduce the cost of providing mobile broadband by 40 to 50 per cent (Mckinsey \& Company, 2009). Introducing mobile service allocation to the $694-790 \mathrm{MHz}$ band in addition to the existing broadcasting service allocation is considered as facilitating partial spectrum flexibility. Hence, it is argued that spectrum ecosystem actors tend to adopt concept such flexibility in indirect ways if there are clear benefits.

The role of international organizations has changed from being a reflector of the interests of countries and a forum for debate to an influence on the objectives and preferences of countries (Viotti and Kauppi, 2007). International regimes could play an interlocking role as they influence national policy preferences and integrate the preferences of the majority of countries as well as the singular interests of norm entrepreneurs (Ratto-Nielsen, 2006). Ryan (2012) argues that the ITU creates a cycle of regulatory lock-in, where national regulators are legally and culturally bound by the treaty-making nature of the ITU.

The ITU is still the focal point for discussion of spectrum issues for many countries as it is the most inclusive international ICT governance forum (MacLean, 2003). Therefore, while the rules and decision-making procedures of the international spectrum management regime were challenged in the WRC-12, the main principles and norms are still accepted from the majority. 


\section{Conclusions}

In order to overcome the emerging spectrum divide resulting from deficiencies inherent to the current spectrum management regime, two alternatives have been discussed: spectrum trading and spectrum commons. While the former calls for allowing spectrum usage flexibility, the later promotes the concept of spectrum open access to all users. Meanwhile, national regulators have been heavily regulating spectrum usage, and the international spectrum management regime has been focusing on global harmonization of spectrum allocation. The main rational behind that is the management of interference between radio stations.

The notion of a "spectrum ecosystem" enables us to understand the complex set of relationships and interactions between actors and perspectives within the international spectrum policy domain. The spectrum ecosystem can be divided into four main layers - applications, technologies, frequency assignments and service allocations - associated respectively with four main actors - end user, the industry, national regulators, and the ITU-R. Within the WRCs, four main aspects of the spectrum are discussed: type of service, type of access, allocation geographical areas and technology characteristics.

WRC-12 discussed three main issues. The first issue that it discussed was enhancement of the international spectrum regulatory framework, while the second was the regulatory measures required to introduce CRS technologies. The third key issue that was discussed at WRC-12 was the allocation of additional spectrum allocation to mobile service. After much discussion, the WRC-12 decided not to change the current international radio regulations with regard to the first two issues and agreed to the third issue. 
One possible explanation is that introducing flexibility is against the traditional service allocation ethos of the ITU-R and does not bring about new business opportunities for the industry. Furthermore, the WRC-12 decision on CRS can be explained by the fact that if the conference decided to introduce specific regulatory measures with regard to CRS, this may engender calls for a similar approach for other emerging technologies. On the other hand, the WRC-12 decision on mobile service has shown how the behaviour of some actors in the spectrum ecosystem has an impact on the other actors, and the increasing direct and indirect influence of the developing countries and the industry, respectively, in the ITU-R.

It is argued that the main implications of WRC-12 on the spectrum ecosystem are that most of actors in the spectrum ecosystem do not support the concept of spectrum flexibility associated with trading, and that the concept of spectrum open access is not under consideration. In addition, the mobile allocation issue has proven that the main driver for change in the spectrum ecosystem are business opportunities for industry and clear benefits for national regulators.

The movement towards change in the international spectrum management regime is led by a minority of the spectrum ecosystem actors, and thus has not yet reached the point at which the regime could change. Resistance from most ITU countries to spectrum trading and spectrum commons is because both regimes weaken state control over spectrum and challenge the main principles and norms of the international spectrum management regime. Having said this, WRC12 highlighted the lack of conformity with the main rule of the regime - regional spectrum allocation in the ITU three regions - and resistance to slow decision making procedures found within the ITU. In conclusion, while the rules and decision-making procedures of the 
international spectrum management regime were challenged in the WRC-12, the main principles and norms are still accepted from the majority. 


\section{References}

ABERNATHY, K. Q. 2004. Why the World Radiocommunication Conference Continues to be Relevant Today. Fedral Communications Law Journal, 56.

AKALU, R. \& ARIAS, A. D. 2012. Assessing the policy of spectrum trading in the UK. Info, 14. ANKER, P. \& LEMSTRA, W. 2011. Governance of Radio Spectrum: License Exempt Devices. In: LEMSTRA, W., HAYES, V. \& GROENEWEGEN, J. (eds.) The Innovation Journey of Wi-Fi: The Road to Global Success. Cambridge University Press.

APT 2011a. Common Proposals for the Work of the Conference. Agenda Item 1.2. World Radiocommunication Conference (WRC-12). Geneva.

APT 2011b. Common Proposals for the Work of the Conference. Agenda Item 1.19. World Radiocommunication Conference (WRC-12). Geneva.

APT 2011c. Common Proposals for the Work of the Conference. Agenda Item 8.2. World Radiocommunication Conference (WRC-12). Geneva.

ASMG 2003. Arab States Common proposal. World Radiocommunications Conference 2003. Geneva.

ASMG 2011a. Arab States Common Proposals. Common Proposals for the Work of the Conference. Agenda Item 1.2. World Radiocommunication Conference (WRC-12). Geneva.

ASMG 2011b. Arab States Common Proposals. Common Proposals for the Work of the Conference. Agenda Item 1.19. World Radiocommunication Conference (WRC-12). Geneva.

ASMG 2011c. Arab States Common Proposals. Common Proposals for the Work of the Conference. Agenda Item 8.2. World Radiocommunication Conference (WRC-12). Geneva.

ATU 2011a. African Common Proposals for the Work of the Conference. Agenda Item 1.19. World Radiocommunication Conference (WRC-12). Geneva.

ATU 2011b. African Common Proposals for the Work of the Conference. Agenda Item 8.2. World Radiocommunication Conference (WRC-12). Geneva.

BARAN, P. 1995. Is the UHF Frequency Shortage a Self Made Problem? Marconi Centenniel Symposium. Bologna.

BENKLER, Y. 1998. Overcoming Agoraphobia: Building the Commons of the Digitally Networked Environment. Harvard Journal of Law and Technology, 11.

BENKLER, Y. 2011. Open Wireless vs. Licensed Spectrum: Evidence from Market Adoption. Draft Working Paper.

BEUTLER, R. 2012. Results of the WRC-12 from a European Broadcaster's Perspective. LS Summit 2012.

BILLQUIST, S. 2010a. European Pressure Grows for 2016 Global IMT Spectrum Action. PolicyTracker.com [Online]. [Accessed 30/6/2012].

BILLQUIST, S. 2010b. Mobile Industry to Press Spectrum Needs in 2016 World Conference Preparations. PolicyTracker.com [Online]. [Accessed 30/4/2012].

BILLQUIST, S. 2010c. WRC Preparatory Talks Look Positive for Cognitive Proponents. PolicyTracker.com [Online]. [Accessed 30/4/2012].

CAVE, M. 2002. Review of Radio Spectrum Management, An independent review for Department of Trade and Industry and HM Treasury.

CAVE, M., DOYLE, C. \& WEBB, W. 2007. Essentials of modern spectrum management, Cambridge ; New York, Cambridge University Press. 
CAVE, M., FOSTER, A. \& JONES, R. W. 2006. Radio Spectrum Management: Overview and Trends. ITU Workshop on Market Mechanisms for Spectrum Management. Geneva, Swiss.

CAVE, M. \& WEBB, W. 2003. Designing Property Rights for the Operation of Spectrum Markets. Papers in Spectrum Trading.

CEPT 2003. WRC-03: European Common Proposals for the Work of the Conference.

CEPT 2011a. European Common Proposals for the Work of the Conference, Part 1, Agenda Item 1.2. World Radiocommunication Conference (WRC-12). Geneva.

CEPT 2011b. European Common Proposals for the Work of the Conference, Part 19, Agenda Item 1.19. World Radiocommunication Conference (WRC-12). Geneva.

CEPT 2011c. European Common Proposals for the Work of the Conference, Part 30, Agenda Item 8.2. World Radiocommunication Conference (WRC-12). Geneva.

CHADUC, J. \& POGOREL, G. 2008. The Radio Spectrum.Managing a Strategic Resource, London, ISTE Ltd.

CITEL 2012a. Inter-American Proposals for the Work of the Conference. Agenda Item 1.2. World Radiocommunication Conference (WRC-12). Geneva.

CITEL 2012b. Inter-American Proposals for the Work of the Conference. Agenda Item 1.19. World Radiocommunication Conference (WRC-12). Geneva.

CITEL 2012c. Inter-American Proposals for the Work of the Conference. Agenda Item 8.2. World Radiocommunication Conference (WRC-12). Geneva.

CLEGG, A. W. 2012. Results from the 2012 World Radiocommunication Conference [Spectrum Policy and Regulatory Issues]. IEEE Wireless Communications, 19.

COASE, R. H. 1959. The Federal Communications Commission. Journal of Law \& Economics, 2, 1-40.

CODDING, G. A. 1991. Evolution of the ITU. Telecommunications Policy, 15.

CODDING, G. A. \& RUTKOWSKI, A. M. 1982. The International Telecommunication Union in a Changing World, Washington, Artech House.

COWHEY, P. F. 1990. The International Telecommunications Regime: The Political Roots of Regimes for High Technology. International Organization, 44.

DONG, H., HUSSAIN, F. K. \& CHANG, E. 2007. Exploring the Conceptual Model of Digital Ecosystem. Second International Conference on Digital Telecommunications.

EL-MOGHAZI, M., WHALLEY, J. \& CURWEN, P. 2008. Is Re-farming the Answer to the Spectrum Shortage Conundrum? Management Science Working Paper. University of Strathclyde.

ELECTRONIC COMMUNICATIONS COMMITTEE (ECC) 2011. Description of Practices Relative to Trading of Spectrum Usage Rights. ECC Reports.

EUROPEAN UNION. 2007. Wider Choice for Users Through More Flexible Radio Spectrum Use: Frequently Asked Questions [Online]. Available: http://europa.eu [Accessed 30/6 2012].

FINNEMORE, M. \& SIKKINK, K. 1998. International Norm Dynamics and Political Change. International Organization, 52.

FRANSMAN, M. 2010. The New ICT Ecosystem: Implications for Policy and Regulation, Cambridge University Press.

GAVRILOV, T. 2003. Results of the WRC-03. Regional Radiocommunication Seminar. Lusaka.

GAWER, A. 2010. Towards a General Theory of Technological Platforms. The Summer Conference 2010 on "Opening Up Innovation: Strategy, Organization and Technology". London.

GILDER, G. 1994. Auctioning the Airways. Forbes. 
GSMA 2012. Licensing to Support the Mobile Broadband Revolution.

HAZLETT, T. W. 1998. Assigning Property Rights to Radio Spectrum Users: Why Did FCC License Auctions Take 67 Years? Journal of Law and Economics, 42.

IRION, K. 2009. Separated Together: The International Telecommunications Union and Civil Society. International Journal of Communications Law and Policy, 13.

ITU-R 1995. WRC-95 Recommendation 34. Principles for the Allocation of Frequency Bands. Provisional Final Acts - World Radiocommunication Conference (WRC-95).

ITU-R 2003a. CPM Report on Technical, Operational and Regulatory/Procedural Matters to be Considered by the 2003 World Radiocommunication Conference.

ITU-R 2003b. Resolution 951: Options to Improve the International Spectrum Regulatory Framework. Provisional Final Acts - World Radiocommunication Conference (WRC-03).

ITU-R 2007a. Resolution 805. Agenda for the 2011 World Radiocommunication Conference. Provisional Final Acts - World Radiocommunication Conference (WRC-07).

ITU-R 2007b. Resolution 956. Regulatory Measures and Their Relevance to Enable the Introduction of Software-Defined Radio and Cognitive Radio Systems. Provisional Final Acts - World Radiocommunication Conference (WRC-07).

ITU-R 2007c. WRC-07 Recommendation 207: Future IMT Systems.

ITU-R 2007d. WRC-07 Resolution 223: Additional Frequency Bands Identified for IMT. Provisional Final Acts - World Radiocommunication Conference (WRC-07).

ITU-R 2007e. WRC-07 Resolution 225: Use of Additional Frequency Bands for the Satellite Component of IMT. Provisional Final Acts - World Radiocommunication Conference (WRC07).

ITU-R 2007f. WRC-07 Resolution 951: Options to Improve the International Spectrum Regulatory Framework. Provisional Final Acts - World Radiocommunication Conference (WRC-07).

ITU-R 2008a. Appendix 4, Annex 1:Characteristics of Stations in the Terrestrial Services. Radio Regulations.

ITU-R 2008b. Article 4: Assignment and Use of Frequencies. Radio Regulations.

ITU-R 2008c. Article 5: Frequency Allocations. Radio Regulations.

ITU-R 2008d. Final List of Participants (Geneva, 18-24 June 2008) The 1st meeting of Working Party $1 B$ Geneva.

ITU-R 2008e. Preamble. Radio Regulations.

ITU-R 2009a. Final List of Participants - Geneva, 17-23 September 2009 The 3rd meeting of Working Party $1 B$ Geneva.

ITU-R 2009b. Final List of Participants (Seoul, 25 February - 4 March 2009) The 2nd meeting of Working Party $1 B$ Seoul.

ITU-R 2010a. Final List of Participants - Working Party 1B (Geneva, 1-10 February 2010) The 4th meeting of Working Party $1 B$ Geneva.

ITU-R 2010b. Final List of Participants - Working Party 1B (Geneva, 21-28 June 2010) The 5th meeting of Working Party $1 B$ Geneva.

ITU-R 2011a. Annex 5 to Working Party 1B Chairman's Report: Working Document Towards a Preliminary New Report ITU-R SM.[RES. 951].

ITU-R 2011b. CPM Report on Technical, Operational and Regulatory/Procedural Matters to be Considered by the 2012 World Radiocommunication Conference.

ITU-R 2011c. Final List of Participants - Working Party 1B (Geneva, 25 May-1 June 2011) The 6th meeting of Working Party $1 B$ Geneva. 
ITU-R. 2012a. Frequently Asked Questions, Notification [Online]. Available: http://www.itu.int [Accessed 26/4/2012.

ITU-R 2012b. ITU-R Resolution 58: Studies on the Implementation and Use of Cognitive Radio Systems.

ITU-R 2012c. WRC-12 Recommendation 16: Interference Management for Stations that May Operate Under More than One Terrestrial Radiocommunication Service. Provisional Final Acts - World Radiocommunication Conference (WRC-12).

ITU-R 2012d. WRC-12 Recommendation 76 Deployment and Use of Cognitive Radio Systems.

ITU-R 2012e. WRC-12 Resolution 233. Studies on Frequency-Related Matters on International Mobile Telecommunications and Other Terrestrial Mobile Broadband Applications. Provisional Final Acts - World Radiocommunication Conference (WRC-12).

ITU-R 2012f. WRC-12 Resolution 804: Principles for Establishing Agendas for World Radiocommunication Conferences. Provisional Final Acts - World Radiocommunication Conference (WRC-12).

ITU-R 2012g. WRC-12 Resolution 957: Studies Towards Review of the Definitions of Fixed service, Fixed Station and Mobile Station. Provisional Final Acts - World Radiocommunication Conference (WRC-12).

ITU-R 2012h. WRC-12 Resolution 232. Use of the Frequency 694-790 MHz by the Mobile, Except Aeronautical Mobile, Service in Region 1 and Related Studies. Provisional Final Acts - World Radiocommunication Conference (WRC-12).

ITU-R 2012i. WRC-12 Resolution 807: Agenda for the 2015 World Radiocommunication Conference. Provisional Final Acts - World Radiocommunication Conference (WRC-12).

ITU-R. 2012j. WRC-12 Weekly Highlights. [Accessed 19/3/2012].

ITU-R. 2012k. WRC-12 Weekly Highlights. [Accessed 19/3/2012].

ITU. 2007. ITU Radiocommunication Assembly Approves New Developments for Its 3G Standards. Press Release [Online]. [Accessed 30/4/2012].

ITU 2011a. Constitution of the International Telecommunication Union. Collection of the Basic Texts of the ITU Adopted by the Plenipotentiary Conference (Ed 2011)

ITU 2011b. Convention of the International Telecommunication Union. Collection of the Basic Texts of the ITU Adopted by the Plenipotentiary Conference (Ed 2011)

ITU. 2012. Academia Membership [Online]. Available: http://www.itu.int [Accessed 30/6 2012].

JAKHU, R. S. 2000. International Regulatory Aspects of Radio Spectrum Management. Workshop on $3 G$ Reforms: Policy and Regulatory Implications. India.

KRASNER, S. 1982. Structural Causes and Regime Consequences: Regimes as Intervening Variables. International Orginzation, 36.

KRUSE, E. 2002. From Free Privilege to Regulation: Wireless Firms and the Competition for Spectrum Rights Before World War I. The Business History Review, 76.

LECG 2009. Economic Impact of Broadband: An Empirical Study.

LEVIN, H. J. 1971. The invisible Resource; Use and Regulation of the Radio Spectrum, Johns Hopkins Press.

LOUIS, J. 2011. International Radio Spectrum Management Beyond Service Harmonisation. Fourth International Conference on Emerging Trends in Engineering \& Technology.

LOUIS, J. \& MALLALIEU, K. 2007. Investigating the Impact of Convergence on the International Spectrum Regulatory Framework. Proceedings of the Second International Conference on Systems and Networks Communications ICSNC '07 Washington D.C. 
LYALL, F. 2011. International Communications: The International Telecommunication Union and The Universal Postal Union, UK, Ashgate Publishing Ltd.

MACLEAN, D. 1995. A New Departure for the ITU: An Inside View of the Kyoto Plenipotentiary Conference. Telecommunications Policy, 19.

MACLEAN, D. 2003. The Quest for Inclusive Governance of Global ICTs: Lessons from the ITU in the Limits of National Sovereignty. Journal of Information Technologies and International Development 1.

MAITRA, A. 2004. Wireless Spectrum Management. Policies, Practices, and Conditioning Factors., The McGraw-Hill Companies.

MANNER, J. A. 2003. Spectrum Wars: The Policy and Technology Debate, Artech House.

MARSHALL, P. F. 2010. A Potential Alliance for World-Wide Dynamic Spectrum Access. IEEE Symposium on New Frontiers in Dynamic Spectrum Access Networks. Singapore.

MAZAR, H. 2009. An Analysis of Regulatory Frameworks for Wireless Communications, Societal Concerns and Risk: The Case of Radio Frequency (RF) Allocation and Licensing. $\mathrm{PhD}$, Middlesex University.

MCCORMICK, P. 2007. Private sector influence in the International Telecommunication Union. Info, 9.

MCKINSEY \& COMPANY 2009. Mobile Broadband for the Masses: Regulatory Levers to Make it Happen.

MELODY, W., SUTHERLAND, E. \& TADAYONI, R. 2005. Convergence, IP Telephony and Telecom Regulation: Challenges \& Opportunities for Network Development, with Particular Reference to India. Workshop on Convergence, VoIP and Regulation. New Delhi.

NOAM, E. 1995. Taking the Next Step Beyond Spectrum Auctions - Open Spectrum Access. IEEE Communications Magazine, 33, 66-73.

NOAM, E. 1998. Spectrum Auctions: Yesterday's Heresy, Today's Orthodoxy, Tomorrow's Anachronism. Taking the Next Step to Open Spectrum Access. Journal of Law \& Economics, 41, 765-790.

OBERST, G. 2012. EU and the Results of the WRC-12 (The Space Perspective). International Regulations of Space Communications: Current Issues. University of Luxembourg.

OFCOM 2012a. Securing Long Term Benefits from Scarce Spectrum Resources. A strategy for UHF bands IV and V.

OFCOM 2012b. UK Report of the ITU World Radio Conference (WRC) 2012.

RANCY, F. 2012. Outcome of WRC-12 for Mobile Broadband. Middle East Spectrum Conference 2012. Bahrain.

RATTO-NIELSEN, J. 2006. The International Telecommunications Regime: Domestic Preferences and Regime Change, lulu.com.

RAUSAS, M. P. D., MANYIKA, J., HAZAN, E., BUGHIN, J., CHUI, M. \& SAID, R. 2011. Internet Matters: The Net's Sweeping Impact on Growth, Jobs, and Prosperity. McKinsey Global Institute.

RCC 2011a. Common Proposals by the RCC Administartions on WRC-12 Agenda Item 1.2. World Radiocommunication Conference (WRC-12). Geneva.

RCC 2011b. Common Proposals by the RCC Administartions on WRC-12 Agenda Item 1.19. World Radiocommunication Conference (WRC-12). Geneva.

RCC 2011c. Common Proposals by the RCC Administartions on WRC-12 Agenda Item 8.2. World Radiocommunication Conference (WRC-12). Geneva. 
RCC 2012. Analysis of the Proposal Regarding Allocation of the Frequency Band 694-790 MHz to the Mobile Service in Region 1 at WRC-12. World Radiocommunication Conference (WRC-12). Geneva.

RSPG 2011. Report on Collective Use of Spectrum (CUS) and Other Spectrum Sharing Approaches.

RSPG 2012. Commission Services' Discussion Paper on the Future Use of the $700 \mathrm{MHz}$ Band in the European Union.

RYAN, P. S. 2012. The ITU and the Internet's Titanic Moment. Stanford Technology Law Review, 8.

SARDENBERG, R. C. T. 2010. Technoeconomic Aspects of Next-Generation Telecommunications Including the Internet Service. PhD, Florida Atlantic University.

SAVAGE, J. 1989. The Politics of International Telecommunications Regulation, London, Westview Press.

SIMS, M. 2012. Interview with Francois Rancy, Director of the ITU Radio Communication Bureau PolicyTracker.com [Online]. [Accessed 30/4/2012].

STANDEFORD, D. 2011. Qualcomm and Nokia Propose Authorised Shared Access to Spectrum. PolicyTracker.com [Online]. [Accessed 30/4/2012].

STANDEFORD, D. 2012a. Europe Scrambles to Craft Unified $700 \mathrm{MHz}$ Plan. PolicyTracker.com [Online]. [Accessed 30/6/2012].

STANDEFORD, D. 2012b. Mobile Broadband Tops Arab Countries' Agenda for WRC-12. PolicyTracker.com [Online]. [Accessed 30/4/2012].

STANDEFORD, D. 2012c. White Space Technologies Supporting Mobility are Several Years Away, FCC Official Says. PolicyTracker.com [Online]. [Accessed 23/7/2012].

STANDEFORD, D. 2012d. WRC Agrees on Several Items but Mobile Broadband Issues Remain Unresolved. PolicyTracker.com [Online]. [Accessed 30/4/2012].

STRUZAK, R. 2003. Introduction to International Radio Regulations. In: RADICELLA, S. M. (ed.) ICTP Lecture Notes. Italy: The Abdus Salam ICTP.

THE WORLD BANK 2009. Information and Communications for Development: Extending Reach and Increasing Impact.

USA 2003. World Radiocommunications Conference 2003: Proposals for the Work of the Conference.

VIOLA, C. 2012. Ofcom Calls for Common European Approach to Dynamic Spectrum Access. PolicyTracker.com [Online]. [Accessed 30/6/2012].

VIOTTI, P. R. \& KAUPPI, M. V. 2007. International Relations and World Politics. Security, Economy, Identity, New Jersy, Pearson.

WAZ, J. \& WEISER, P. 2011. Internet Governance: The Role of Multistakeholder Organizations. The Silicon Flatirons Roundtable Series on Entrepreneurship, Innovation, and Public Policy.

WELLENIUS, B. \& NETO, I. 2005. The Radio Spectrum: Opportunities and Challenges for the Developing World. World Bank Policy Research Working Paper, 3742.

WOMERSLEY, R. 2012a. Laying the Groundwork for Future UHF Success. PolicyTracker.com [Online]. [Accessed 30/6/2012].

WOMERSLEY, R. 2012b. Spectrum Struggles - Broadcasters Face Pressure on $700 \mathrm{MHz}$. [Accessed 30/6/12].

WOOLLEY, F. M. 1995. International Frequency Regulation and Planning. EBU Technical Review, Spring. 
YUNCUIA, F. \& GANGB, H. 2011. Analysis on Synergetic Evolution of Telecommunications Industrial Ecosystem Based on Ecology Theory. Energy Procedia, 13.

ZARKIN, M. J. 2006. Microeconomic Ideas, Policy Epistemologies, and the Politics of Spectrum Licensing, 1922-1997. Polity, 38. 